\title{
Implementing and Evaluating a Blended Learning Format in the Communication Internship Course
}

\author{
Christina M. Smith \\ California State University Channel Islands, Camarillo, CA, USA \\ christina.smith@csuci.edu
}

\begin{abstract}
The use of blended learning is well suited for classes that involve a high level of experiential inquiry such as internship courses. These courses allow students to combine applied, face-to-face fieldwork activities with a reflective academic component delivered online. Therefore, the purpose of this article is to describe the pedagogical design and implementation of a pilot blended learning format internship course. After implementation, the pilot class was assessed. Results of the survey and focus group revealed high levels of student satisfaction in the areas of course structure, faculty-student interaction, and application of theory to the "real-world" experience undertaken by students during the internship. Lower levels of satisfaction with the course's academic rigor and a sense of community were also reported. Notably, students with experience in blended learning expressed lower levels of overall satisfaction, but reported higher levels of satisfaction with the course's rigor and sense of community. The paper concludes by offering implications for instructors seeking to implement blended learning approaches.
\end{abstract}

Keywords: blended learning, internship, Communication, assessment, community

\section{Introduction}

The use of blended learning has increased dramatically in higher education (Jeffrey, Milne, Suddaby, \& Higgins, 2014). While definitions of blended learning vary, all involve the combination of face-to-face instruction with online learning in a unified and complementary manner (Glazer, 2012). A full definition and discussion is provided in the Study Context section. The growing popularity of blended learning is due to a number of factors, including increased pressure to serve more students with fewer resources, demands of flexibility from students, and greater retention rates (Garrison \& Vaughan, 2008). Studies report higher levels of student satisfaction due to the increased interaction and motivation resulting from hybrid formats (Fabry, 2012; Sorden \& Munene, 2013). Additionally, faculty report higher satisfaction levels in their interactions with students when using a blended course format (Ho, Lu, \& Thurmaier, 2006). These factors

Material published as part of this publication, either on-line or in print, is copyrighted by the Informing Science Institute. Permission to make digital or paper copy of part or all of these works for personal or classroom use is granted without fee provided that the copies are not made or distributed for profit or commercial advantage AND that copies 1) bear this notice in full and 2) give the full citation on the first page. It is permissible to abstract these works so long as credit is given. To copy in all other cases or to republish or to post on a server or to redistribute to lists requires specific permission and payment of a fee. Contact Publisher@,InformingScience.org to request redistribution permission. have led to widespread institutional support of blended learning. In fact, a recent Center for Digital Education survey found that $90 \%$ of faculty respondents noted their university encouraged blended approaches ("Realizing the Full Potential," 2012).

Jelfs, Nathan, and Barrett (2004) contend that hybrid approaches involve "blending of the learning into students' 
lives" (p. 87). Thus, blended learning is particularly well suited for classes that involve a high level of fieldwork or experiential inquiry. An internship course is well suited to this design because it allows students to combine applied, "real-world" fieldwork activities with a reflective academic component.

As noted by Jeffrey, Milne, Suddaby, and Higgins (2014), there is a lack of research on the teaching practices surrounding blended learning, or how "teachers balance the blend." This is particularly important considering that "only by understanding current practice can we prepare to make changes to that practice." Therefore, the purpose of this article is to address the lack of research on blending learning teaching practices by presenting a case study in the design, execution and evaluation of an internship course delivered using this format.

First, the context for the case study, including literature on hybrid course design and online Communication and internship courses, is provided. Next is a description of the conception of the course and selection of technological tools. I then provide an overview of course activities, including the module structure, assignments, and discussion prompts. Then, the case study's evaluation, which consisted of a survey and focus group, is reviewed. This is followed by the results and discussion section. The paper concludes with implications and future directions for instructors of blended learning courses.

\section{Study Context}

Definitions of hybrid or blended learning vary from technology-oriented to pedagogically oriented understandings (see Driscoll, 2002). Lord and Lomicka (2008) define blended learning as "combining various types of pedagogy with different tools for interaction and discussion." Often, the definition emphasizes the combination of two existing approaches: wholly online and traditional classroom instruction. Dawley (2007) defines hybrid learning as "online instruction that complements traditional instruction and tailors the needs of individual students" (p. 2). Garrison and Vaughan (2008) point out that blended learning involves three key assumptions: the thoughtful integration of both online and face-to-face learning, an emphasis on student engagement in course design, and the replacement of traditional on-campus contact hours. Hybrid courses potentially allow instructors to capitalize on the strengths of both instructional modes. However, little agreement exists as to the optimal combination of a number of instructional and organizational elements within the blended learning environment, including space, time, and humanness (Graham, 2006; Khechine, Lakhal, Pascot, \& Bytha, 2014).

There are many important aspects to consider when preparing to construct and deliver a hybrid or blended online/face-to-face learning experience. Regarding the pragmatic components, Ko and Rossen (2004) suggest that instructors first discern which components work best in each medium. Moreover, they suggest that in designing a blended course, instructors must refine the processes of orientation, facilitation, and preparation, staying mindful of transitions, pacing, and setting clear expectations for their students. Again, considering students in an internship course simultaneously complete several hours of applied work outside of class time, these elements became central to a successful experience.

In terms of internships, web-based technologies offer a way to facilitate off-campus learning opportunities for students with numerous prior commitments (O'Keefe Bazzoni, 2000). The ability for students to apply communication theory outside the classroom is highly beneficial to their curricular experience. Mattern (2003) details an approach to internships whereby public relations practitioners would guide students in fieldwork that applied their classroom knowledge. Given that most programs will not have the resources to execute this type of individualized approach, a blended learning-based approach provides a mechanism for students to obtain course credit while engaging in instructor-facilitated experiences. 
Blended and online learning is not new in the field of Communication. Courses in Organizational Communication have implemented a variety of technologies to enhance student learning, including Skype to train students in the art of online/remote interviewing (Garner \& Buckner, 2013) and the construction of an online public speaking class (Linardopoulos, 2010). While most students surveyed indicated that their preference for an online public speaking course was based on convenience, nearly $80 \%$ of students felt that their learning was the same as students on-campus and most believed that their public speaking skills increased as a result of completing the course. Additionally, scholars have investigated instructor perceptions of implementing technology in Communication courses. Using Professional Communication as a case study, Freeman and Tremblay (2013) designed seven online modules and interviewed instructors at the end of the semester. Results were mixed, but did suggest that student-instructor engagement underwent a positive shift.

In the fall of 2013 the Communication Internship course at a California State University was redesigned for delivery in a blended learning format. The author participated in a professional development program that sought to provide resources and peer feedback for instructors converting a course to a blended learning format. This is commendable considering the widespread lack of institutional support for online course design (Garrison \& Vaughan, 2008). The Blended Learning Preparation Program implemented a cohort model to teach faculty about "course design, technologies and pedagogy regarding teaching in a blended learning environment" (http://www.csuci.edu/tlt/blpp.htm). The faculty collaborated in a series of workshops and presented the results of their re-design at the end of the semester. Faculty were also encouraged to formally evaluate the course after its implementation the following semester. The resulting evaluation serves as the case study for this investigation.

The re-designed Internship course was intended to replace the existing format that asked students completing an internship to simply write a final 3-page reflective paper. Program faculty were concerned that this approach lacked rigor. Moreover, students did not interact with one another (and very little with the instructor) during the course of the semester, leading to a lack of community in the course. In the re-designed Internship course, students implemented a variety of technologies, including Google Presentations, blogs, and ScoopIt to perform weekly module-based activities. Additionally, each module-based section of the re-designed course had specific objectives addressing various aspects of communication theory, research, and writing.

\section{Course Design and Implementation}

The re-designed internship course had two primary goals: first, the instructor sought to increase the academic rigor of the class, and second, the instructor wanted to bolster the sense of community among students in the class. Regarding the former goal, the instructor sought to foster a "community of inquiry" among students enrolled. This approach "supports connection and collaboration among learners and creates a learning environment that...will precipitate and sustain critical reflection and discourse" (Garrison \& Vaughan, 2008, p. 8). Each element - social presence, teaching presence, and cognitive presence - was addressed in the re-design. Additionally, a second but related goal was to increase the interaction among students and foster community. In this case, community can be understood as things like trust, common learning goals, and interaction (Rovai, 2002). Students potentially "feel isolated from the instructor and other class members" which can lead to problems (Davidson-Shivers \& Rasmussen, 2006, p. 18). Thus, building technologically based mechanisms to ensure a sense of community became one focus of the redesign effort.

A sense of community also results from a high level of student engagement. As noted by Jeffrey et al. (2014), this is accomplished in two ways. First, the course must create a sense of social presence, defined as “the teacher's enthusiasm and the extent to which students feel a part of the 
class" (p. 129). As Sorden and Munene (2013) point out, social presence is positively linked with many desirable outcomes such as student engagement, retention, and overall satisfaction. Engagement is maintained by providing students with a clear structure, instructions, and assessment criteria, as well as timely feedback. In this case, the course was broken into three one-month modules, with an in-class orientation meeting at the beginning of the semester and a final meeting at the end where students delivered a presentation on their internship. In between these class meetings, each module was structured similarly for consistency. It was believed that consistency among modules would be easier for both the instructor in designing the course and the students (half of whom had little online course experience) in completing the activities on schedule.

The next step was to examine various technologies to execute the online components of coursework. As Smith (2008) contends, designing a learner-centered online course is key to its success. The instructor utilized the Blackboard interface to construct and deliver the course content. As noted, each module was presented as a unit to students and contained similar content. Due to the wide availability and use of Google by students, Google Presentations were chosen for the knowledge and application-based activities. For the evaluation component, a WordPress blog was created for students to use for reflection. In addition to the original post, students were required to respond to classmates, thus facilitating interaction. While it was originally believed that such online interaction would be effective in bolstering community, student feedback still suggested a lack of connection with classmates (see below). Students were also asked to engage with an online news curation service called "ScoopIt." This technology allowed students to locate relevant news articles about internships, careers in Communication, and job-related information and add their unique interpretations to the article. Finally, for convenience, students were provided a variety of options for completing an individual meeting component with the instructor (in person via office hours, online using Skype, or via phone).

\section{Course Activities}

Students accessed all materials for a module under a single page, including instructions, readings and resources, assignment descriptions, and links to the Google Presentation and blog. The home page included a welcome video where the instructor offered an introduction, his or her background, and walked students through the online course site using a screencast technology (please see Appendix A for a screenshot of the course home page). Before the first class meeting (held on campus) students were asked to complete a "Pre-Module." This was meant to serve as a primer and build social presence (Jeffrey et al., 2014). The goal was to familiarize them with the various technologies as well as to begin building community. In addition to offering his or her name and picture, hometown, and internship position, each student was asked to give three questions that would be answered during the first class meeting.

Each subsequent module proceeded similarly: it began with a weeklong Google Presentationbased assignment whereby students were asked to utilize resources provided to answer a series of prompts. Several resources and readings were provided and students were allowed to choose among them or to locate their own, fostering open and purposeful inquiry (Garrison \& Vaughan, 2008). The prompts consisted of three questions that each addressed a different level of Bloom's Taxonomy. To address the knowledge component, the first two prompts asked for a definition of key concepts, asking students to identify the factual terminology involved. To address the comprehension component, the third prompt allowed students to compare different categories. Finally, to address the application component, the fourth prompt asked students to find another example of the concept (please see Appendix B for learning module materials). For example, the module on organizational assimilation and culture asked the following questions... 
1. Define assimilation and note how it is achieved (knowledge).

2. Outline the concept of organizational culture (knowledge).

3. How do assimilation and culture connect (comprehension)?

4. Peters and Waterman suggest Disney is an organization with a strong culture. What organizations do you think have a strong culture (application)?

In week two, analysis and synthesis were addressed when students were asked to review the entire Google Presentation and blog about their own unique experience. In particular, they were asked to compare and contrast their internship experience with the criteria presented the previous week...

In what ways did the concepts presented on organizational assimilation and culture compare and contrast with your own experience in entering your organization?

These two weeks' worth of exercises provided the cognitive presence for the course (Garrison \& Vaughan, 2008).

In the third week, students were required to meet with the instructor using their preferred format. This gave the instructor the opportunity to troubleshoot problematic internship incidents, offer advice on communication-related issues, or to motivate students struggling with online coursework. Indeed, as Jeffrey et al. (2014) suggest, personal contact is the best mechanism for reengaging those "who have drifted away." As a follow-up, students were asked to complete an online journal (accessible only to the instructor) that noted the outcome of the week's conversation.

Please reflect on the information, tools, and/or resources you have applied from our oneon-one meeting this week. Be specific.

These exercises were intended to create a sense of discipline among students and to bolster the teaching presence during weeks of online instruction (Garrison \& Vaughan, 2008).

Finally, in the fourth week, students met together as a class to complete a facilitated discussion on topics related to classroom content. Such in-class meetings served as the primary mechanism for maintaining social presence among students and between student and instructor. Again, for the module on organizational assimilation and culture, students were broken into small groups according to their internship experience and asked to answer the following...

Develop a set of "best practices" for organizations in XXX to communicate the organizational culture and to efficiently and effectively assimilate interns into that culture. Be prepared to share the results of your discussion with the class.

The second module addressed organizational leadership, with prompts that asked students to explore the concept in scholarly literature and interview a leader in their organization. In the final module, the instructor sought to connect the Internship experience with Communication Program Learning Outcomes, providing students with a "bigger picture" view of their work experience. Therefore, they were asked to utilize the news curation tool called "ScoopIt" to locate and annotate articles of relevance to Communication students.

ScoopIt is a site that allows for collecting, archiving, and annotating/curating news stories related to a specific topic. Based on your experience in completing Communication coursework, and a hands-on experience through the internship, please complete the following: Locate 3 articles related to Communication, Internships, Employment, etc and link them to our Internship ScoopIt site. For each article, include a 50-100-word annotation that describes the article's importance to students interested in completing internships in the future. Alternatively, you can note why Communication students in general 
should be interested in exploring the article's contents. This site will be required reading for Internship students next semester.

Their blog post for this module was also different in content. Instead of responding directly to a set of resources given by the instructor, students were asked to offer feedback on the Communication Program's effectiveness in career preparation...

Read 2-3 annotated articles from our ScoopIt site and apply the material to your internship position. Based on your readings, reflect on how you were trained to take on this position. Post a 200-word response to the following prompt on your blog:

What was the most rewarding class you took at the university?

What was the most useful class, based on your internship experience?

What do you believe are the strengths of the current Communication Program in terms of career preparation?

How can the Communication Program better meet the needs of its students in terms of career preparation?

\section{Research Design and Methodology}

To measure the effectiveness of the Communication Internship course's re-design and use of technology, it was assessed after the first semester of implementation using both a survey and focus group. Such summative assessments help the instructor and other interested parties measure the overall impact of the course (Davidson-Shivers \& Rasmussen, 2006). In the case of the Communication Internship course, two means of assessing the pilot class were performed. First, a brief survey was administered to students during the final in-class session, and second, a focus group was conducted with students enrolled in the course.

\section{Participants}

The participants consisted of 11 upper division undergraduate students at a California State University. 4 students were male and 7 were female and the average age was 22.7. 9 were Communication majors, 1 was a Communication minor, and 1 was a Business major. All Communication students were focusing on organizational communication and non-profit leadership in their studies. The Internship course was completed in fulfillment of an elective and students performed their internships in communication-related positions at organizations located both oncampus and off-campus. Six students had not completed a blended learning-format course in the past, whereas five had previous experience with blended learning.

\section{Survey}

As noted, on the final day of class, students were asked to complete a survey to assess the course's effectiveness. In order to minimize instructor influence, a member of the university's Teaching and Learning Innovation team administered the survey. Students were not graded on completion of the survey and were informed its completion was completely voluntary. The survey consisted of a series of nine 5-item likert scale questions ranging from 1 (strongly disagree) to 3 (neutral) to 5 (strongly agree) and addressed overall student satisfaction, the use of technology, the course structure and expectations, instructor interaction and feedback, the academic rigor of the class, and the sense of community fostered. Overall student satisfaction (SATISFACTION) was measured by asking students to agree or disagree with "In general, I was satisfied with the blended learning Internship course." The use of technology (TECHNOLOGY) was measured by asking students to agree or disagree with "Technology was utilized effectively in the course." 
Expectations (EXPECTATIONS) were measured by asking students to agree or disagree with "Course expectations and grading standards were clearly articulated." Instructor interaction (INTERACTION) was measured by asking students to agree or disagree with "The feedback and interaction provided by the instructor was useful." The course's academic rigor (RIGOR) was measured by asking students to agree or disagree with "I found the internship course to be academically rigorous." The course's exploration of Communication theory (THEORY) was measured by asking students to agree or disagree with "The internship course increased my understanding of communication theories and practices." The internship's ability to increase workforce experience (WORKFORCE) was measured by asking students to agree or disagree with "The internship course increased my workforce experience and made me a more competitive applicant for jobs." The ability of assignments to connect theory to the real world (CONNECTION) was measured by asking students to agree or disagree with "The assignments served to clearly connect communication theory with the real world." The sense of community in the course (COMMUNITY) was measured by asking students to agree or disagree with "The internship course built a strong sense of community among students."

\section{Focus Group}

In addition to the survey, a focus group was conducted with students. Focus groups allow participants to be stimulated by each other's ideas and experiences (Lindlof \& Taylor, 2002). Focus groups also allow researchers "to explore group characteristics and dynamics as relevant constitutive forces in the construction of meaning and the practice of social life" (Kamberelis \& Dimitriads, 2005, p. 902). In this sense, group interaction can often produce richer data than dialogue. The focus group was conducted by the same Teaching and Learning Innovation team member on campus on the final day of class and lasted approximately 60 minutes. Questions focused on the overall student experience, what students found effective and ineffective about the course structure and content, and workload. Additionally, questions asked about the interactions between instructor and student, as well as student-student interactions.

\section{Results and Discussion}

Overall, students indicated a high level of satisfaction with the re-designed course, with $73 \%$ satisfied or very satisfied, $27 \%$ neutral, and no students reporting dissatisfaction (see Figure 1).

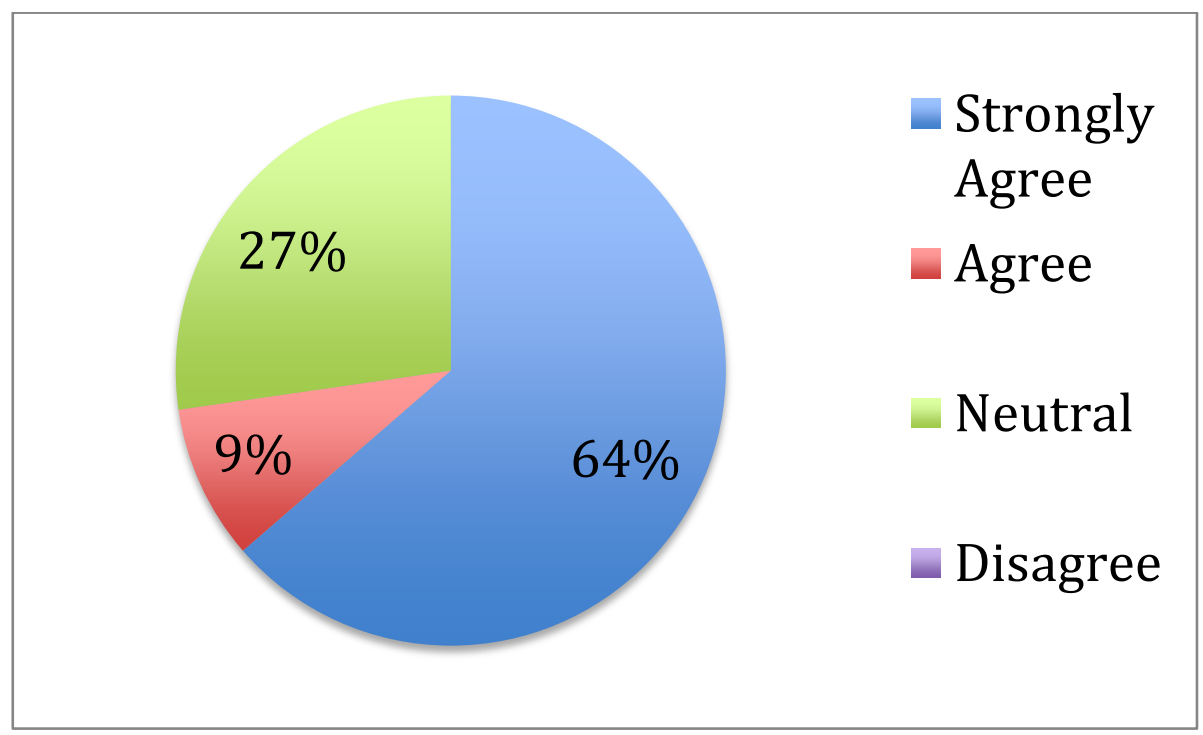

Figure 1: SATISFACTION 
Descriptive statistics are provided below (see Table 1). The item with which students indicated the highest level of agreement was developing their experience for the workforce (WORK-

FORCE, mean $=4.63$ ). The next two items with high levels of agreement included helping students to apply the concepts and theories learned in the Communication curriculum to their experience in the field $(C O N N E C T I O N$, mean $=4.36)$ and helping them to increase their understanding of Communication theory (THEORY, mean $=4.00)$. Regarding the structure, organization, and instructor interaction, students indicated a high level of satisfaction with the use of technology $(T E C H N O L O G Y$, mean $=4.36)$ and the instructor-student interaction in the course $($ INTERACTION, mean $=4.45)($ see Figure 2$)$.

Table 1: Results of Survey

\begin{tabular}{|c|c|c|c|c|}
\hline Variable & Mean & $\begin{array}{c}\text { Standard } \\
\text { Deviation }\end{array}$ & $\begin{array}{l}\text { Minimum } \\
\text { Value }\end{array}$ & $\begin{array}{l}\text { Maximum } \\
\text { Value }\end{array}$ \\
\hline SATISFACTION & 4.36 & 0.924 & 3 & 5 \\
\hline TECHNOLOGY & 4.36 & 0.809 & 3 & 5 \\
\hline EXPECTATIONS & 3.90 & 1.221 & 2 & 5 \\
\hline INTERACTION & 4.45 & 0.688 & 3 & 5 \\
\hline RIGOR & 3.72 & 0.786 & 3 & 5 \\
\hline THEORY & 4.00 & 0.775 & 3 & 5 \\
\hline WORKFORCE & 4.63 & 0.505 & 4 & 5 \\
\hline CONNECTION & 4.36 & 0.809 & 3 & 5 \\
\hline COMMUNITY & 3.54 & 0.820 & 2 & 5 \\
\hline
\end{tabular}

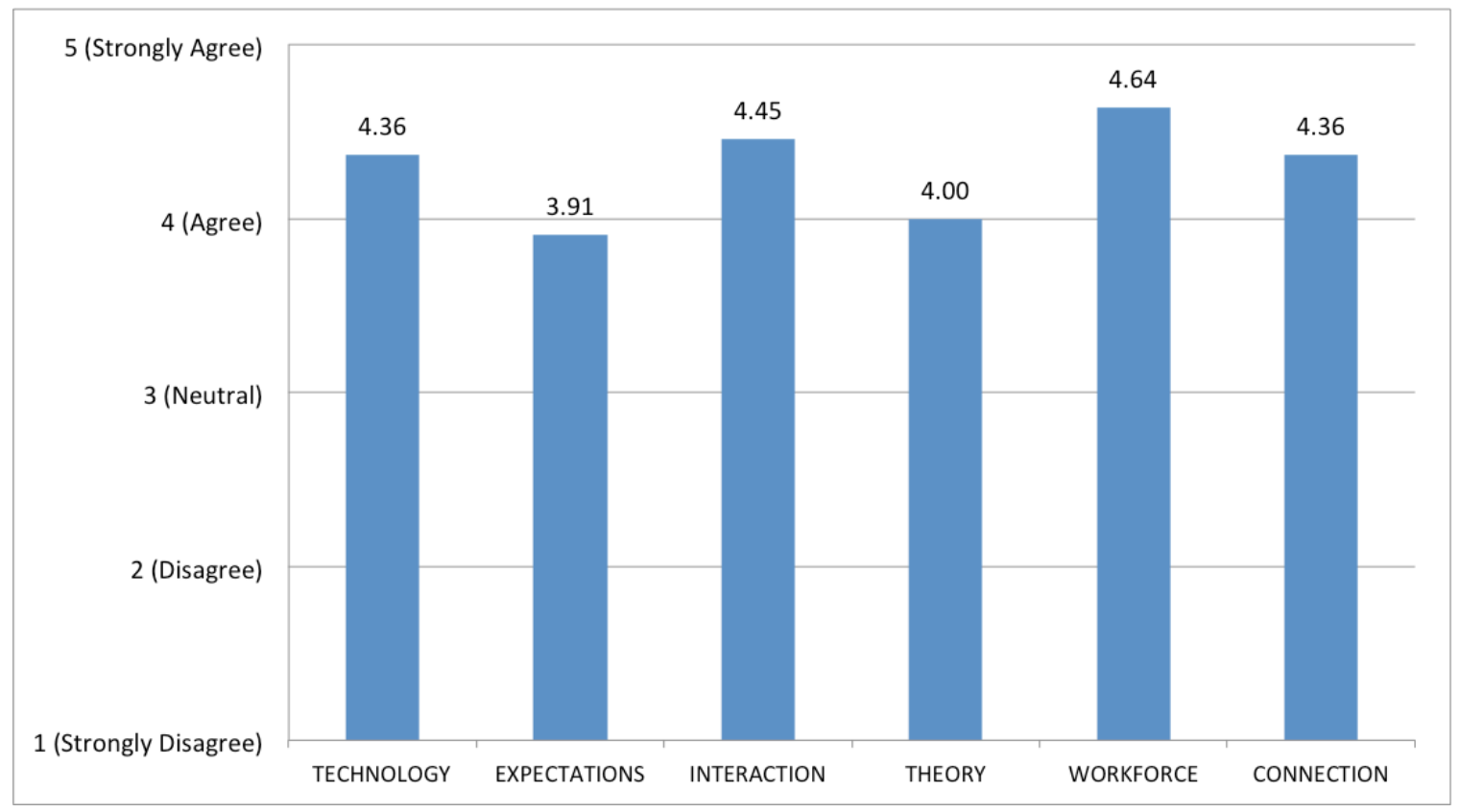

Figure 2: High Levels of Agreement 
Open-ended responses on the survey mirrored these results. Students noted that they "felt like it provided a lot of opportunities to apply information" and that "this class required me to use what I have learned so far in the community." Other open-ended comments indicated that the course was successful in "application of theories in real world" and "the practical nature of the concepts."

However, students indicated the lowest levels of agreement with the academic rigor of the redesigned class $(R I G O R$, mean $=3.72)$. Moreover, the sense of community fostered in the blended learning environment $(C O M M U N I T Y$, mean $=3.54)$ received the lowest reported score on the survey (see Figure 3).

Furthermore, the less effective elements listed on open-ended responses included "the lack of face-to-face time with other students" and that "there was no face-to-face communication with lessons." These results could be due in part to the overall student experience in the Communication program at the university. Program hallmarks include close faculty-to-student interaction and mentoring, widespread group work, and highly interactive teaching methods across classes. Thus, students may have higher expectations for the amount and quality of student-student interaction based on their face-to-face learning experience. Alternatively, students may not have understood the notion of rigor as asked on the survey. Nevertheless, the results suggest the need to continue refining this element.

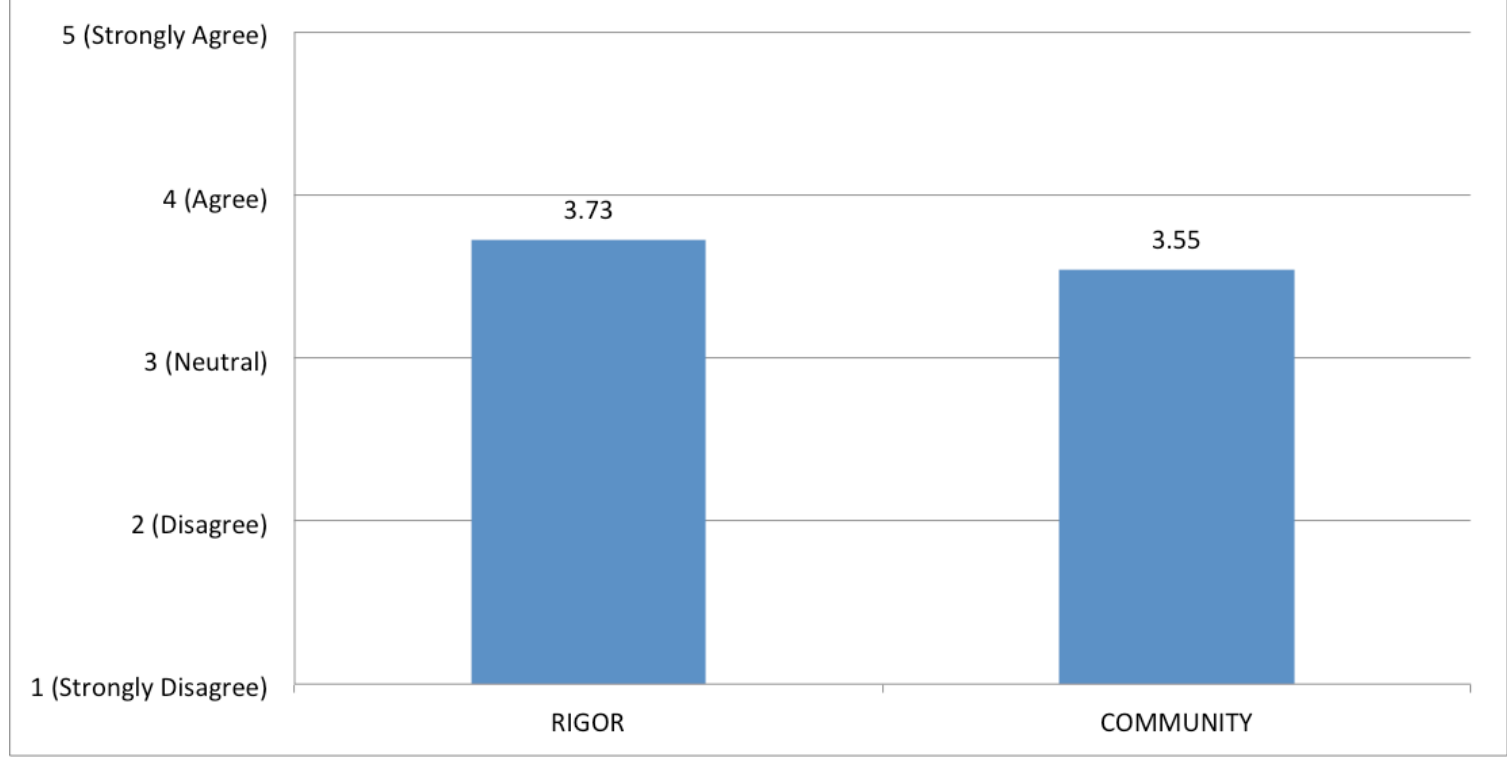

Figure 3: Low Levels of Agreement

A comparison was made between the satisfaction levels of students that reported having previously taken a blended learning format course and those that had not (see Figure 4). Results suggested that overall satisfaction levels were lower among students with prior experience (SATISFACTION mean of 3.8 vs. 4.8). Lower scores were also reported on the use of technology (TECHNOLOGY mean of 4.2 vs. 4.5), faculty-student interaction (INTERACTION mean of 4.2 vs. 4.6), and increased experience for the workforce (WORKFORCE mean of 4.4 vs. 4.8). Questions addressing Communication theory received mixed results. While students that had previously completed a blended learning course reported less agreement with the course's ability to connect theory to the "real world," (CONNECTION mean of 4.2 vs. 4.5) they reported higher agreement with 
the course's ability to increase their overall knowledge of Communication theory (THEORY mean of 4.2 vs. 3.8).

Finally, in the two measures that received the lowest overall levels of agreement, students with previous blended experience reported higher levels of satisfaction: academic rigor (RIGOR mean of 3.8 vs. 3.6) and sense of community (COMMUNITY mean of 3.6 vs. 3.5). Considering the university is only beginning to implement blended learning approaches into its overall curriculum, most students may not yet be accustomed to such approaches and are therefore using their understanding of face-to-face classes to inform their responses. For students with previous online learning experience, the course actually is meeting its goals of increasing academic rigor and a sense of community.

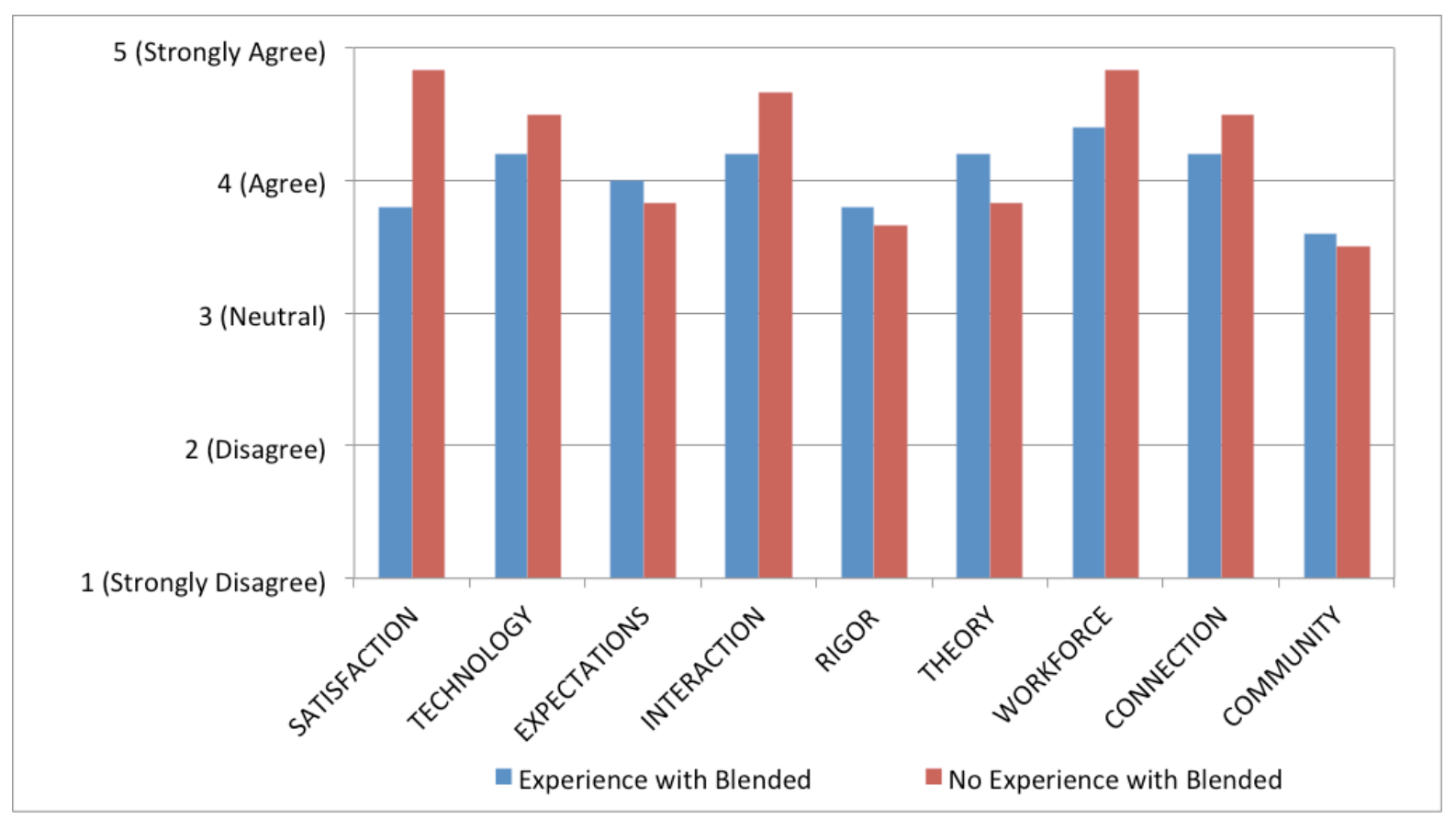

Figure 4: Comparison of Previous Blended Learning Experience

Results from the focus group mirrored findings from the survey (see Table 2). Students indicated satisfaction with the instructor feedback and interaction, the applied nature of the coursework and lack of "busywork," and the use of key technologies such as ScoopIt. This technology was positively received by students for the ability to locate, curate, and post relevant news articles. Students indicated a surprisingly high satisfaction level with using this technology, suggesting the assignment allowed them to be exposed to outside ideas and information. Students in the course indicated that they perceived a lack of community and student-to-student interaction in the pilot course. Thus, while in the end students reported a positive experience with the re-designed blended learning format of the Communication internship course, future implementations should continue exploring ways to increase substantive interaction and a sense of community among students. 
Table 2. Focus Group Themes

\begin{tabular}{|c|c|}
\hline Theme & Illustrative Student Comments \\
\hline Course activities & $\begin{array}{l}\text { "I felt that the work that we were supposed to do was not busywork } \\
\text { - it was just quick and to the point" (Student R). } \\
\text { "I felt like the course treated us like adults. It was, here's the in- } \\
\text { formation - now go apply it" (Student T). }\end{array}$ \\
\hline $\begin{array}{l}\text { Connecting coursework to } \\
\text { "real world" }\end{array}$ & $\begin{array}{l}\text { "Actually realizing how your Communication classes correlate with } \\
\text { working" (Student C1). } \\
\text { "It was kindof like the best of both worlds - in having some school, } \\
\text { class where you're learning some stuff but also real world experi- } \\
\text { ence" (Student R). } \\
\text { "It actually made the connection between theory and real-life expe- } \\
\text { rience" (Student C2). }\end{array}$ \\
\hline Use of technology & $\begin{array}{l}\text { Use of ScoopIt to "post articles from online that pertain to our class } \\
\text { and pertain to the business world...there were articles that I never } \\
\text { would have thought of that were real interesting. It was someone } \\
\text { else's perspective, someone else looking at it. Sometimes they put } \\
\text { different universities in different parts of the country and those dif- } \\
\text { ferent perspectives were nice to read" (Student M). }\end{array}$ \\
\hline Sense of community & $\begin{array}{l}\text { "Was potentially lost in technology" (Student E) } \\
\text { "I didn't feel like there was a lot of togetherness, just because our } \\
\text { work wasn't together" (Student R). } \\
\text { "When you limit the amount of class sessions that you have, I feel } \\
\text { like we all missed out on friendship" (Student C2) } \\
\text { "I think its community in the best way it could've been. With the } \\
\text { technology its not gonna be really tight knit. But for what it was } \\
\text { worth, I think it did the best it could" (Student E). }\end{array}$ \\
\hline Academic rigor & $\begin{array}{l}\text { The workload was "a lot for me. Um, just because the nature of my } \\
\text { internship, combined with my other classes and, and then on top of } \\
\text { that, since, there was also online work" (Student C2). } \\
\text { "We are spending lots of hours in our internship so I don't think } \\
\text { there should be a heavy workload because the work we are doing is } \\
\text { within our jobs" (Student C1). }\end{array}$ \\
\hline
\end{tabular}

\section{Implications}

The results of the survey and focus group on the pilot internship course provided an opportunity to explore implications for faculty interested in designing and implementing blended learning in similar classes. Findings revealed the following considerations for all instructors: (1) setting clear expectations for students, (2) clearly structuring the course and communicating evaluation measures, and (3) being strategic in the overall implementation of blended courses.

In terms of the first point, student focus group participants recognized the need for discipline and professionalism in taking any online-based coursework. They suggested that successful students 
must be organized, motivated, and articulate to succeed. This is in line with the findings of Napier, Dekhane, and Smith (2011), where students in a blended learning course identified discipline and autonomy as essential for success. Thus, instructors should communicate these necessary traits to students early in the course. Often, the addition of a "wisdom wall" is a useful mechanism for this activity. Here, former students offer advice for those about to take the course, allowing students to access information from their peers (Pacansky-Brock, 2012).

In terms of the second point, student participants recommended that instructors must be clear and consistent with online content, structure, and grading expectations. Such qualities are aligned with Ko and Rossen's (2004) suggestions for designing a blended learning course. Especially in an internship course, students must be given sufficient time for both the reflective, academic component, as well as the applied fieldwork component.

Finally, and in line with existing literature on blended learning, such approaches must be intentional: "good instructional design is vitally important to the success of a blended learning course, perhaps even more so than in a traditional classroom or in fully online courses (Glazer, 2012, p. 5). As universities increasingly pressure faculty to utilize hybrid and online approaches, it is necessary that intentionality guide all decisions to modify a course's delivery modality. In his review of the key problems and opportunities afforded by increased technology in education, Vaughan (2007) reports that administrators see one of the top benefits of blended learning as its ability to reduce costs and space demands. On the other hand, faculty reported that, while blended learning courses require additional time for planning and development, often there is a lack of support from the administration for these key tasks. Furthermore, professional development in acquiring and applying technology is often lacking as well. The disconnect between faculty and administrator perceptions may be one reason that a recent poll by Inside Higher Ed found that most faculty are still skeptical of online learning (Strausheim, 2014). Institutions must be willing to commit resources if blended learning approaches are to be implemented effectively.

As Freeman and Tremblay (2013) point out in their study of an Introduction to Professional Communication course delivered in a hybrid format, "where blended learning is imposed, faculty may not have the opportunity to make the pedagogical transition to a blended teaching environment and may experience a disconnect between their existing pedagogical approach and the requirements of online instruction." Ultimately, faculty must be offered the support necessary to produce blended learning courses that elicit buy-in in order to maximize the benefits of this approach.

This evaluation of the pilot internship course also revealed both strengths and areas for improvement in the redesigned course itself. As a result, the instructor must continue refining the course to improve these elements while maintaining the successful elements. In the future, the technology VoiceThread will be utilized for the course in place of the Google Presentation. It is thought that this technology, which allows for textual, audio, and video responses, will help foster a stronger sense of interaction among students than the static, text-based predecessor. Existing studies demonstrate that it successfully elicits student responses (Pecot-Hebert, 2012).

VoiceThread could potentially increase the sense of community and student-to-student interaction by allowing students to hear one another's voices or see webcam images of respondents.

\section{Conclusion}

As indicated, there is currently a lack of research on blended learning teaching practices (Jeffrey et al., 2014). Moreover, there are few studies that have investigated blended teaching practices surrounding internship courses. Blending such courses facilitates the experiential application of concepts and theories and assists students in obtaining job-related skills. Indeed, faculty in the health care and education fields are starting to explore how blended learning environments can be 
effectively utilized (LaFrance \& Beck, 2014; Mahnken, Baumann, Meister, Schmitt, \& Fischer, 2011). In the case of an experiential learning experience, the role of the instructor becomes that of mentor. Instead of disseminating information to students, the instructor must help students to make the connection between theory and praxis. Such a relationship is key for a course like the internship, which does not involve set content like other courses. Rather, the main purpose of the internship is to allow students to test their knowledge and skills in a specific organizational setting.

Thus, as O'Keefe Bazzoni (2000) points out, a blended learning approach is particularly well suited for these types of courses. Blended learning allows instructors to utilize technology to provide the necessary theoretical grounding, while face-to-face time can be dedicated to interpersonal discussion and guidance. This lets instructors capitalize on one of the strengths reported by faculty having taught in a blended format: the novel ways of communicating and increased quality of interaction with students afforded by technology (Vaughan, 2007).

This paper described the design, implementation and evaluation of a pilot blended learning internship course in the field of Communication. The course was the first one in the Communication program at the university to be designed and implemented in this format. In addition to inclass meetings, three technology-based modules were designed to address both key concepts in the field and specific cognitive processes. Results of the summative assessment revealed high levels of student satisfaction in the areas of course structure, faculty-student interaction, application of theory to the "real-world" experience undertaken by students during the internship, and the use of specific technologies. Lower levels of satisfaction with the course's academic rigor and a sense of community were also reported.

As noted in the Study Context, the pilot blended learning internship course replaced a previous iteration of the class where students only completed a brief reflective paper at the end of the semester. In addition to a workload that was not challenging enough, the previous format also did not allow students to interact with one another. Thus, the course was re-designed with the goals of increasing academic rigor and building a stronger sense of community. Though the results suggested that these goals were not met in levels as high as other elements measured, from my perspective, the re-designed class is a dramatic improvement. Students were required to engage with Communication theory throughout the semester (as opposed to only at the end) and were given the opportunity to learn directly from their peers. Furthermore, as previously indicated, the results are potentially influenced by students' lack of experience with online learning coupled with their previous experience in other courses in the Communication Program that stress interpersonal interaction and group work.

The study did have some limitations; primarily, it involved a small sample size of only 11 students - all of whom were relatively similar in terms of educational goals and objectives (all were Business/Communication students performing internships in fulfillment of elective credit). Future research should continue to investigate how internships and other fieldwork-based classes implement a blended learning format to meet the learning objectives of other disciplines. Additionally, the study was limited to a single small California State University whose student population consists of a large number of first generation college students, many of whom struggle to utilize technology. As a result, the findings don't necessarily transfer to universities with more technologically savvy students. Future studies should continue to explore how blended learning approaches can be implemented to effectively serve a diverse student population. 


\section{Appendix A. Screen shot of course home page}

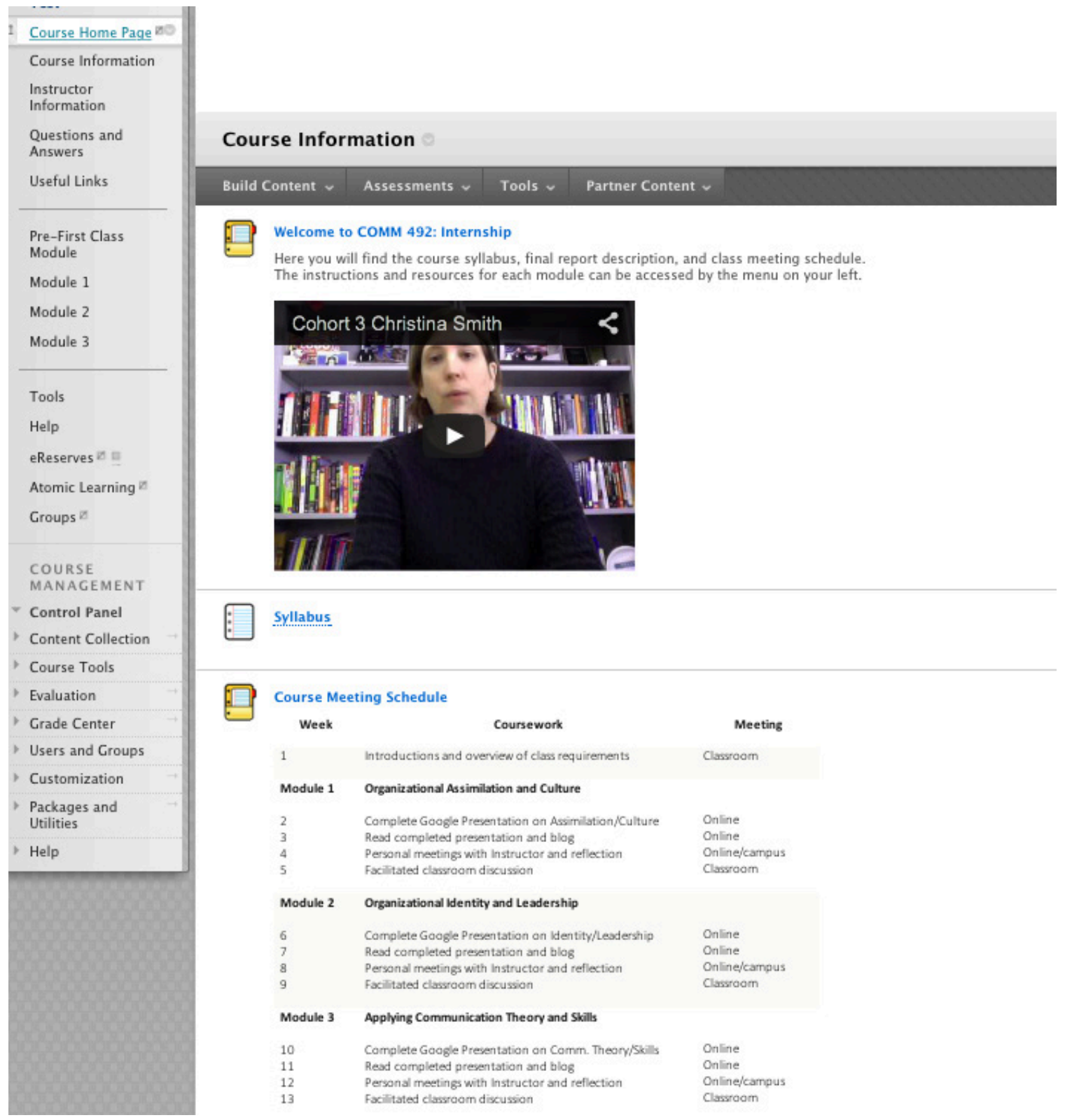




\section{Appendix B. Learning modules}

\section{Module 1: Organizational Assimilation and Culture}

\section{Student Outcomes/Learning Objectives}

1. To explain the three assimilation processes/stages: anticipatory socialization, encounter, and metamorphosis.

2. To identify the history of organizational communication approaches to culture.

3. To apply two or more tools for measuring organizational culture.

4. To reflect on their own organizational assimilation and culture.

\section{Learning Plan/Activities}

1. Using the resources provided and those you find on your own, complete the Google Presentation on organizational assimilation and culture.

Resources: Miller textbook, Chapters 5 (Culture) and 7 (Assimilation)

Article: Pacanowsky and O'Donnell Trujillo on Culture

Article: In Search of Excellence excerpt

Link to Video on Disney

2. In Google presentation, prompts include:

Define assimilation and note how it is achieved.

Outline the concept of organizational culture.

How do assimilation and culture connect?

Peters and Waterman suggest Disney is an organization with a strong culture. What organizations do you think have a strong culture?

3. Complete blog posts that reflect upon the activity.

4. Schedule and attend a one-on-one meeting.

5. Participate in facilitated in-class discussion. Based on the blog entries, the instructor will summarize 3-5 of the common themes that arose. They will then list these on the board and we will go around the room allowing each student to choose one theme that was relevant to them and discuss it for 2-3 minutes.

For the second portion of class, students are grouped together based on similarities (industry, type of organization, location, etc) and are provided a prompt.

\section{Assessment Performance Task}

1. For Google Presentation

There are four prompts. Each student must contribute their own answers (minimum of 50 words each) to at least three.

Make sure to include your author information on your slide.

Posts are due on Saturday at 11:59 PM. 


\section{For Blog Post}

View the completed Google Presentation on organizational assimilation and culture and apply the material to your internship position. Think about how you were assimilated into the organization and the ways in which you learned the culture. Post a 250-word response to the following prompt on your blog:

In what ways did the concepts presented on organizational assimilation and culture compare and contrast with your own experience in entering your organization?

\section{For Individual Meetings}

Ask students to reflect on what they take away or will apply from our one-on-one meetings.

\section{For Facilitated Discussion}

Develop a set of "best practices" for organizations in XXX to communicate the organizational culture and to efficiently and effectively assimilate interns into that culture.

\section{Module \#3: Applying Communication Skills and Knowledge}

\section{Student Outcomes/Learning Objectives}

1. To reflect on the skills and competencies obtained in Communication coursework and how they relate to the overall internship experience.

2. To reflect on how their successes and challenges can assist future Internship students.

\section{Learning Plan/Activities}

1. Using your own experience with the Internship course, please complete 3 posts to our ScoopIt site, a platform meant for archiving and curating news stories related to specific topics.

2. Prompt for ScoopIt site:

ScoopIt is a site that allows for collecting, archiving, and annotating/curating news stories related to a specific topic. Based on your experience in completing Communication coursework, and a hand-on experience through the internship, please complete the following:

Locate 3 articles related to Communication, Internships, Employment, etc and link them to our Internship ScoopIt site.

For each article, include a 50-100-word annotation that describes the article's importance to students interested in completing internships in the future. Alternatively, you can note why Communication students in general should be interested in exploring the article's contents. This site will be required reading for Internship students next semester.

3. Complete blog posts that reflect upon the activity.

4. Schedule and attend a one-on-one meeting.

5. Participate in facilitated in-class discussion. Based on the blog entries, the instructor will summarize 3-5 of the common themes that arose in terms of the Communication Program. They will then list these on the board and we will go around the room allowing each student to choose one theme that was relevant to them and discuss it for 2-3 minutes. 


\section{Assessment Performance Task}

\section{For ScoopIt Site}

There is a prompt on CI Learn that identifies the assignment instructions and goals.

Annotated articles are due on Saturday at 11:59 PM.

2. For Blog Post

Read 2-3 annotated articles from our ScoopIt site and apply the material to your internship position. Based on your readings, reflect on how you were trained to take on this position. Post a 200 -word response to the following prompt on your blog:

a. What was the most rewarding class you took at $\mathrm{CI}$ ?

b. What was the most useful class, based on your internship experience?

c. What do you believe are the strengths of the current CI Communication Program in terms of career preparation?

d. How can the CI Communication Program better meet the needs of its students in terms of career preparation?

3. For Individual Meetings

Ask students to reflect on what they take away or will apply from our one-on-one meetings.

4. For Facilitated Discussion

In groups of 3, students will be asked to create a "Wisdom Wall" for future Internship students. They will be asked to focus on preparing for an internship (including what classes and/or extracurricular activities to undertake) as well as how to best position oneself for a strong internship experience.

\section{References}

Davidson-Shivers, G. V., \& Rasmussen, K. L. (2006). Web-based learning: Design, implementation, and evaluation. Upper Saddle River, NJ: Pearson.

Dawley, L. (2007). The tools for successful online learning. Hershey, PA: Information Science Publishing.

Driscoll, M. (2002). Blended learning: Let's get beyond the hype. Available at http://www07.ibm.com/services/pdf/blended_learning.pdf

Fabry, D. L. (2012). Using student online course evaluations to inform pedagogy. Journal of Research in Innovative Teaching, 5(1), 45-52.

Freeman, W., \& Tremblay, T. (2013). Considerations for supporting the reluctant adoption of blended learning. MERLOT Journal of Online Learning and Teaching, 9. Available at http://jolt.merlot.org/vol9no1/freeman 0313.htm

Garner, J. T., \& Buckner, M. (2013). Skyping class: Using videoconferencing in organizational communication class. Communication Teacher, 27, 1-5.

Garrison, D. R., \& Vaughan, N. D. (2008). Blended learning in higher education: Framework, principles, and guidelines. San Francisco: Jossey-Bass.

Glazer, F. S. (2012). Blended learning: Across the disciplines, across the academy. Steerling, VA: Stylus Publishing. 
Graham, C. R. (2006). Blended learning systems: Definition, current trends, and future directions. In C. J. Bonk \& C. R. Graham (Eds.), The handbook of blended learning: Global perspectives, local designs. Hoboken, NJ: Wiley.

Ho, A., Lu, L., \& Thurmaier, K. (2006). Testing the reluctant professor's hypothesis: Evaluating a blendedlearning approach to distance education. Journal of Public Affairs Education, 81-102.

Jeffrey, L. M., Milne, J., Suddaby, G., \& Higgins, A. (2014). Blended learning: How teachers balance the blend of online and classroom components. Journal of Information Technology Education: Research, 13, 121-140. Retrieved from http://www.jite.org/documents/Vol13/JITEv13ResearchP121140Jeffrey0460.pdf

Jelfs, A., Nathan, R., \& Barrett, C. (2004). Scaffolding students: Suggestions on how to equip students with the necessary study skills for studying in a blended learning environment. Journal of Educational Media, 29, 85-96.

Kamberelis, G., \& Dimitriads, G. (2005). Strategic articulations of pedagogy, politics, and inquiry. In N.K. Denzin \& Y.S. Lincoln (Eds.), Handbook of qualitative research (3rd ed.) (pp. 887-907). Thousand Oaks, CA: Sage.

Khechine, H., Lakhal, S., Pascot, D., \& Bytha, A. (2014). UTAUT model for blended learning: The role of gender and age in the intention to use webinars. Interdisciplinary Journal of E-Learning and Learning Objects, 10, 33-52. Retrieved from http://www.ijello.org/Volume10/IJELLOv10p033052Khechine 0876.pdf

Ko, S., \& Rossen, S. (2004). Teaching online: A practical guide. New York: Routledge.

LaFrance, J. A., \& Beck, D. (2014). Mapping the terrain: Educational leadership field experiences in K-12 virtual schools. Educational Administration Quarterly, 50, 160-189.

Linardopoulos, N. (2010). Teaching and learning public speaking online. MERLOT Journal of Online Learning and Teaching, 6. Available at http://jolt.merlot.org/vol6no1/linardopoulos 0310.pdf

Lindlof, T. R., \& Taylor, B. C. (2002). Qualitative communication research methods. Thousand Oaks, CA: Sage.

Lord, G., \& Lomicka, L. (2008). Blended learning in teacher education: An investigation of classroom community across media. Contemporary Issues in Technology and Teacher Education, 8(2). Retrieved from http://www.citejournal.org/vol8/iss2/general/article1.cfm

Mahnken, A. H., Baumann, M., Meister, M., Schmitt, V., \& Fischer, M. R. (2011). Blended learning in radiology: Is self-determined learning really more effective? European Journal of Radiology, 78, 384387.

Mattern, J. L. (2003). Developing a well-worn path between classroom and workplace through managed experiential learning. North Dakota Journal of Speech and Theatre, 16, 30-34.

Napier, N. P., Dekhan, S., \& Smith, S. (2011). Transitioning to blended learning: Understanding student and faculty perceptions. Journal of Asynchronous Learning Networks, 15, 20-32.

O’Keefe Bazzoni, J. (2000). The electronic internship: The case for asynchronous communication. Business Communication Quarterly, 63, 101-110.

Pacansky-Brock, M. (2012). Best practices for teaching with emerging technologies. New York: Routledge.

Pecot-Hebert, L. (2012). To hybrid or not to hybrid, that is the question: Incorporating VoiceThread technology into a traditional communication course. Communication Teacher, 26, 129-134.

Realizing the Full Potential of Blended Learning. (2012). Center for Digital Education. Retrieved from http://echo360.com/sites/default/files/CDE12\%20STRATEGY\%20Echo360-V.pdf

Rovai, A.P. (2002). Sense of community, perceived cognitive learning, and persistence in asynchronous learning networks. Internet and Higher Education, 5, 319-322. 
Smith, R. M. (2008). Conquering the content: A step-by-step guide to online course design. San Francisco, CA: Jossey-Bass.

Sorden. S. D., \& Munene, I. I. (2013). Constructs related to community college student satisfaction in blended learning. Journal of Information Technology Education: Research, 12, 251-270. Retrieved from http://www.jite.org/documents/Vol12/JITEv12ResearchP251-270Sorden1206.pdf

Strausheim, C. (2014, October 29). Online ed skepticism and self-sufficiency: Survey of faculty views on technology. Retrieved from https://www.insidehighered.com/news/survey/online-ed-skepticism-andself-sufficiency-survey-faculty-views-technology

Vaughan, N. D. (2007). Perspectives on blended learning in higher education. International Journal on ELearning, 6, 81-94.

\section{Biography}

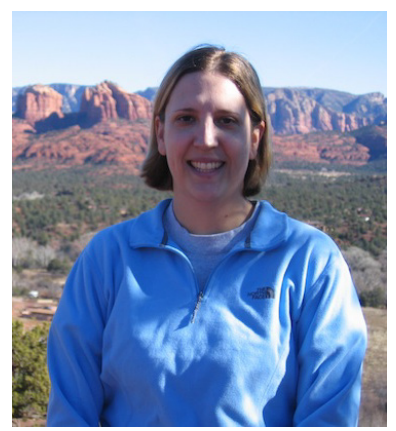

Christina M. Smith is an Assistant Professor of Communication at California State University Channel Islands. She earned her Ph.D. from the Hugh Downs School of Human Communication at Arizona State University. Her research interests are in visual rhetoric, digital media, and public memory. She has published in Critical Studies in Media Communication, Argumentation and Advocacy, and Western Journal of Communication. 